Supporting Information for:

\title{
Sub-Picosecond Production of Solute Radical Cations in THF after Radiolysis
}

Andrew R. Cook*

Chemistry Department, Brookhaven National Laboratory, Upton, New York 11973, United States

Section S1. Radiation chemistry details for aryl-bromide scavengers.

Lifetime of $\mathrm{Br}_{2} \mathrm{~F}^{-}$. Optical Fiber Single-Shot (OFSS) transient absorption following radiolysis of $300 \mathrm{mM}$ 9,9-Dihexyl-2,7-dibromofluorene $\left(\mathrm{Br}_{2} \mathrm{~F}\right)$ in THF at different wavelengths is shown in Figure S1.1 below. Aryl-halides, particularly bromides, are known to rapidly dissociate upon attaching an electron. ${ }^{1}$ The lifetime of $\mathrm{Br}_{2} \mathrm{~F}$ radical anion is uncertain, but likely $<60 \mathrm{ps}$, and probably $\sim 20 \mathrm{ps}$. A problem is that radical anion and cation spectra overlap, and it is not known where the radical anion might be clearly observed. $760 \mathrm{~nm}$ is near the peak absorption for $\mathrm{Br}_{2} \mathrm{~F}^{+\bullet}$; it is expected that part of the 60 ps decay is due to geminate recombination, and part to $\mathrm{Br}_{2} \mathrm{~F}^{\bullet}$ dissociation. Note that for unsubstituted biphenyl and fluorene, radical anions are known to have a peak absorption $\sim 50 \mathrm{~nm}$ to the blue of the radical cations. ${ }^{2}$ It is thus reasonable to expect that the faster $20 \mathrm{ps}$ decay at $710 \mathrm{~nm}$ is due more to $\mathrm{Br}_{2} \mathrm{~F}^{\bullet}$ dissociation than cations. We note however that there should be far more radical anions made than cations, so the smaller signal at $710 \mathrm{~nm}$ may the tail of the decay, with faster components unresolved, making the $\sim 20 \mathrm{ps}$ lifetime an upper limit for the lifetime of the radical anion. It also adds support to the idea that the signal at $760 \mathrm{~nm}$ is predominantly due to radical cations, even at short times. The longer time tail at both 710 and $760 \mathrm{~nm}$ is most certainly due to $\mathrm{Br}_{2} \mathrm{~F}^{+} \bullet$ recombination alone.

Solvated electron absorption is not an important component at 710 or $760 \mathrm{~nm}$, as shown by the trace at $950 \mathrm{~nm}$ where they absorb much more strongly.

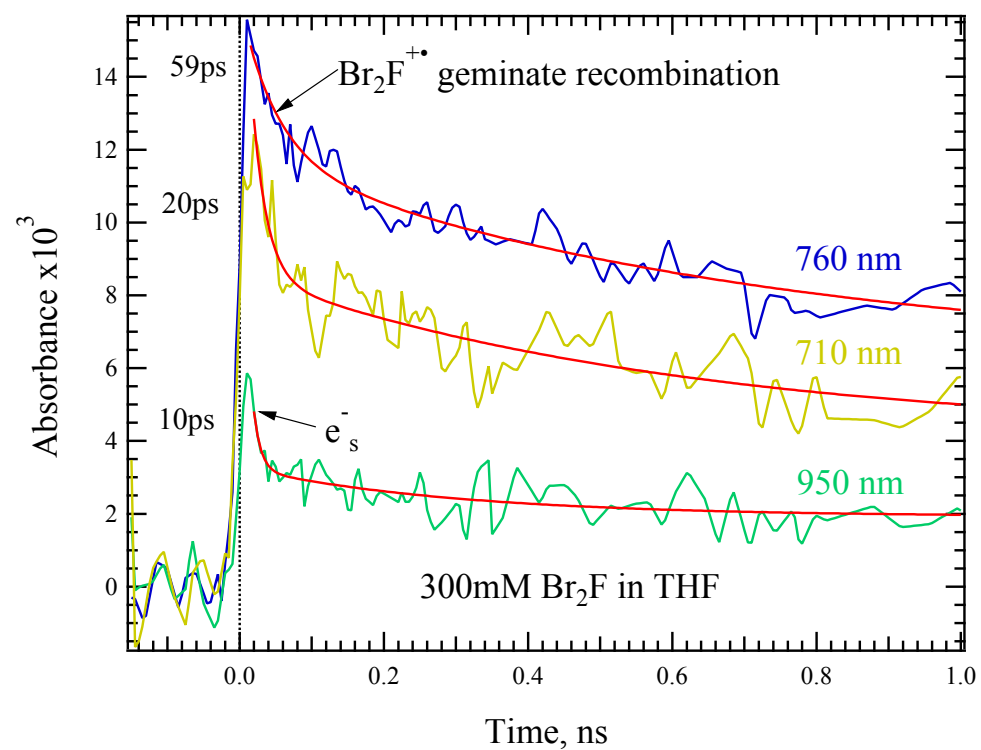

Figure S1.1: Transient absorption of a $300 \mathrm{mM} \mathrm{Br} 2 \mathrm{~F}$ solution in THF following radiolysis at 3 wavelengths, with fits labelled by the lifetime of the $1^{\text {st }}$ decay component. 
Summary of details for all aryl-bromides tested. Table S1.2 below gives determined spectral parameters for the the radical cations of four aryl-bromides tested as candidates as hole scavengers. Anion lifetimes were determined with fits to data such as the ones shown in Figure $\mathrm{S} 1.1$ for $\mathrm{Br}_{2} \mathrm{~F}$. Note that in the previous work, we reported the lifetime of 4-bromobiphenyl radical anion as $\sim 30$ ps. $^{1}$ Here we find a shorter 13.9 ps lifetime, which is expected to be more accurate. The previous value was determined at $800 \mathrm{~nm}$ where the radical cation likely absorbs much more strongly than the radical anion, ${ }^{2}$ giving a decay likely dominated by geminate recombination of the cation rather than radical anion dissociation. Despite the uncertainties in radical anion lifetimes, we find that they are well correlated with the computed barriers (B3LYP/6-31g(d)/THF) for dissociation to make Br- and an aryl radical, as seen in Figure S1.3 below. While the correlation is only 3 points, it gives some support to the assignment of the $\mathrm{Br}_{2} \mathrm{~F}^{\bullet}$ lifetime being $\sim 20 \mathrm{ps}$. In previous work we found a similar $\sim$ linear correlation previously for a wide range of aryl halides. ${ }^{1}$

Experiments also sought to identify new spectral features in concentrated $\mathrm{Br}_{2} \mathrm{~F}$ solutions that might be attributed to dimer radical cations. Such species are known particularly for aromatics like benzene giving new absorptions to the red of the radical cation, but were expected to be unlikely with $\mathrm{Br}_{2} \mathrm{~F}$ due to the terminal bromine atoms and dihexyl side-chains. None were detected.

A possible concern was loss of bromine atoms after radiolysis, as these would have the ability to oxidize many solutes, particularly those with low ionization potentials. Computed dissociation energies for bromine atom loss from radical cations are given in Table S1.2 and are all large and positive, thus loss is very unlikely.

Table S1.2: Summary of aryl-bromide sample parameters

\begin{tabular}{|l|l|l|l|l|l|}
\hline & $\begin{array}{l}\lambda_{\max ^{a}} \\
(\mathrm{~nm})\end{array}$ & $\varepsilon\left(\mathrm{M}^{-1} \mathrm{~cm}^{-1}\right)^{b}$ & $\begin{array}{l}\Delta \mathrm{G}^{(\mathrm{Br})} \\
(\mathrm{eV})^{c}\end{array}$ & $\begin{array}{l}\text { Anion } \\
\text { Lifetime } \\
(\mathrm{ps})\end{array}$ & $\begin{array}{l}\Delta \mathrm{E}_{\text {barrier }} \\
(\mathrm{meV})^{d}\end{array}$ \\
\hline $\begin{array}{l}\text { 9,9-Dihexyl-2,7-dibromofluorene } \\
\left(\mathrm{Br}{ }_{2} \mathrm{~F}\right)\end{array}$ & 775 & 22600 & 3.63 & 19.9 & 14.8 \\
\hline 4-bromobiphenyl & 760 & 17800 & 3.51 & 13.9 & 1.7 \\
\hline 4,4-Bis(bromomethyl)biphenyl & 760 & 16000 & 1.08 & & 23.7 \\
\hline $\begin{array}{l}\text { 2,7-Bis(bromomethyl)-9,9-dihexyl- } \\
\text { 9H-fluorene }\end{array}$ & 710 & 21400 & 1.13 & 23.4 & 26.1 \\
\hline
\end{tabular}

${ }^{a}$ Radical cation absorption spectrum maximum. ${ }^{b}$ Peak radical cation extinction coefficient determined in 1,2-dichloroethane relative to biphenyl as described previously. ${ }^{c}$ Computed free energy for loss of a bromine atom from the radical cation (B3LYP/6-31G(d)). ${ }^{d}$ Computed radical anion dissociation barrier. 

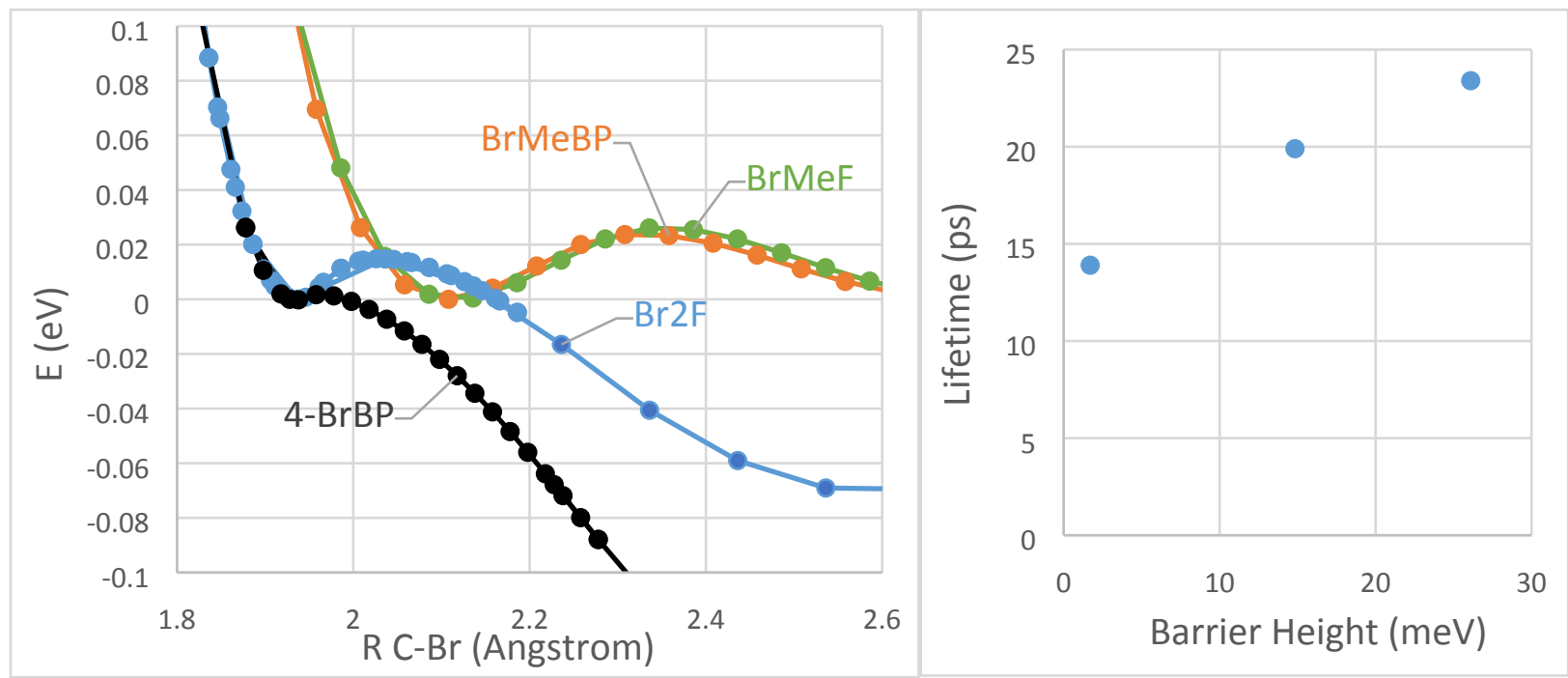

Figure S1.3: Computed radical anion dissociation barriers, B3LYP/6-31+G*/SCRF=THF. Computed barrier heights are well correlated with measured radical anion lifetimes. 
Section S2. Spectral details for $\mathrm{Br}_{2} \mathrm{~F}^{+} \bullet$.

The absorption spectrum of $1 \mathrm{M}$ 9,9-dihexyl-2,7-dibromofluorene $\left(\mathrm{Br}_{2} \mathrm{~F}\right)$ in THF following pulse radiolysis at various delay times is shown in Figure S2.1 below. The spectrum was unchanged when $0.5 \mathrm{M}$ dichloromethane was added. Data were recorded with $\sim 1 \mathrm{~ns}$ time resolution in transient digitizer based experiments where collection of high quality spectra is best. The band peaking at $\sim 775 \mathrm{~nm}$ is the radical cation of $\mathrm{Br}_{2} \mathrm{~F}$, maximized at the earliest times and decreasing at later times. There are 2 other apparent peaks. The peak at $\sim 415 \mathrm{~nm}$ is due to a combination of $\mathrm{Br}_{2} \mathrm{~F}^{+\bullet}$ and ${ }^{3} \mathrm{Br}_{2} \mathrm{~F}^{*}$ formed by recombination. This peak grows from 1 to $2 \mathrm{~ns}$, then decays. At long times this peak appears to blue-shift slightly, when triplets dominate the band. Kinetic modeling at 770 and $420 \mathrm{~nm}$ assuming all recombinations of $\mathrm{Br}_{2} \mathrm{~F}^{+}$and $\mathrm{Br}^{-}$make $\mathrm{Br}_{2} \mathrm{~F}^{*}$, and further all singlets become triplets rapidly suggesting that $\mathrm{Br}_{2} \mathrm{~F}^{+\bullet}$ absorption at $1 \mathrm{~ns}$ is at least $2.55 \mathrm{x}$ larger at $420 \mathrm{~nm}$ than $770 \mathrm{~nm}$; at most $22 \%$ of the $1 \mathrm{~ns}$ peak at $420 \mathrm{~nm}$ is due to ${ }^{3} \mathrm{Br}_{2} \mathrm{~F}^{*}$ absorption. At long times, >> $100 \mathrm{~ns}$, a $3^{\text {rd }}$ band peaking at $540 \mathrm{~nm}$ grows in. This band is attributable to complexes of $\mathrm{Br}$ atoms made during recombination with the aromatic rings of $\mathrm{Br}_{2} \mathrm{~F}$, similar to those described for similar $\mathrm{Cl}$ atom complexes described by Bird. ${ }^{3}$

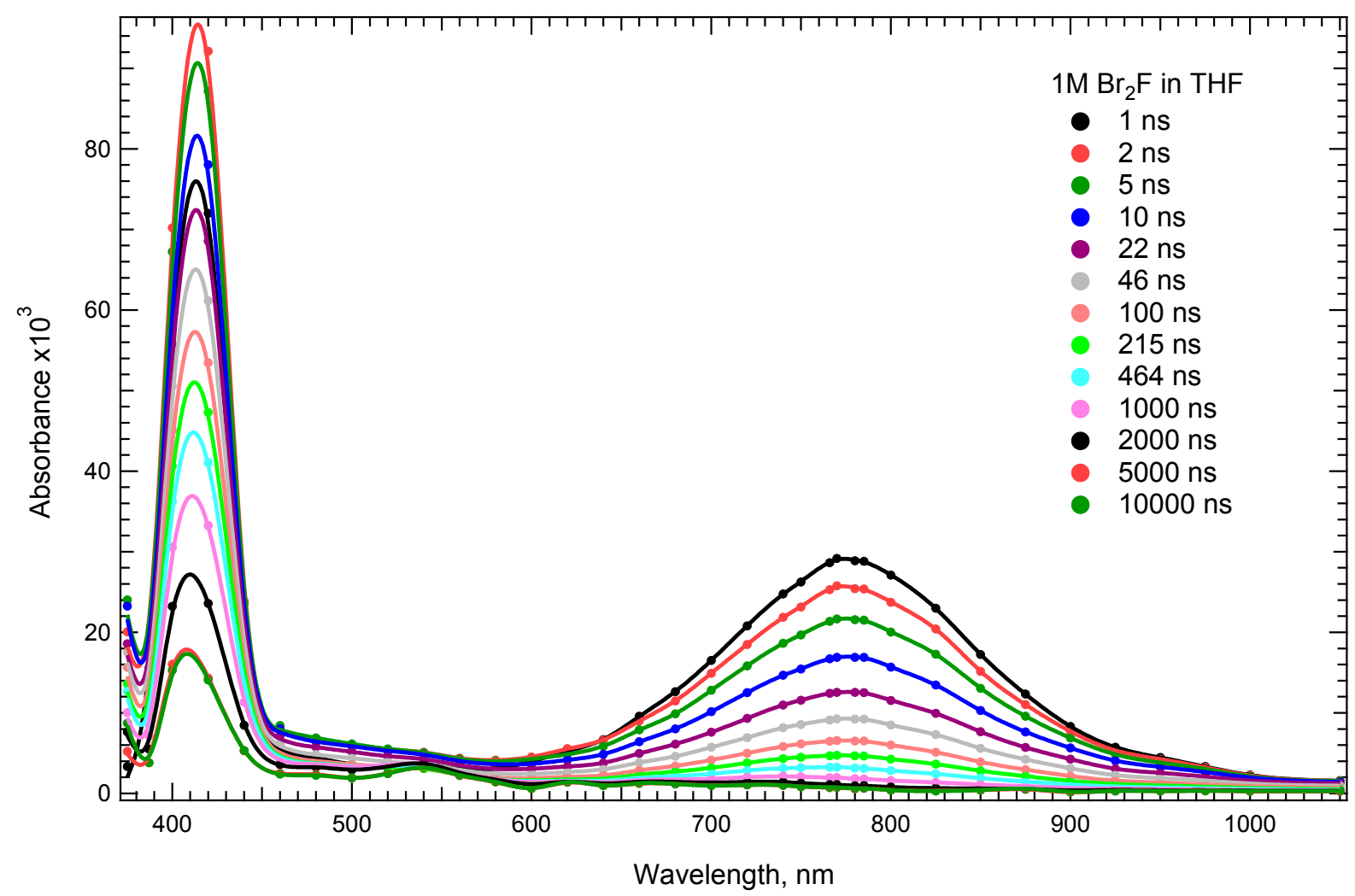

Figure S2.1: Absorption spectra at various delay times following radiolysis of a $\mathrm{Br}_{2} \mathrm{~F}$ solution. 
Section S3. Determination of the $\mathrm{Br}_{2} \mathrm{~F}^{+}$extinction coefficient.

The extinction coefficient of the radical cation was determined by comparison of the absorbance after radiolysis of a $10 \mathrm{mM} \mathrm{Br}_{2} \mathrm{~F}$ solution in 1,2-dichloroethane (DCE) to a $10 \mathrm{mM}$ sample of biphenyl (BP) in DCE. In DCE, radiolysis produces DCE ${ }^{+}$which transfers the positive charge to solutes to make identical concentrations of $\mathrm{BP}^{+\bullet}$ and $\mathrm{Br}_{2} \mathrm{~F}^{+} \bullet$, but no anions because $\mathrm{DCE}^{-}$dissociates rapidly. Data shown below are averages of 3 experiments, each composed of 4 electron pulse shots for consistency. Using the ratio of absorbances and Gould's $\varepsilon=14500 \mathrm{M}^{-1} \mathrm{~cm}^{-1}$ for $\mathrm{BP}^{+\bullet}, 4,5$ we determined $\varepsilon=21085 \pm 10 \% \mathrm{M}^{-1} \mathrm{~cm}^{-1}$ for $\mathrm{Br}_{2} \mathrm{~F}^{+} \bullet$.

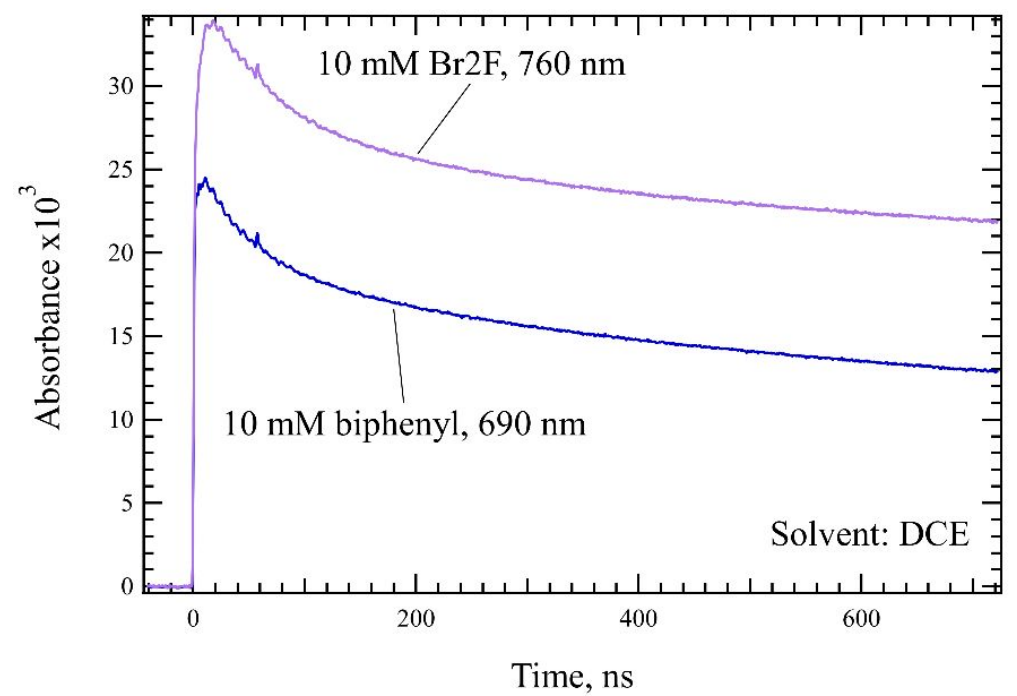

Figure S3.1: Pulse radiolysis data from samples containing either $\mathrm{Br}_{2} \mathrm{~F}$ or biphenyl in 1,2dichloroethane. 
Section S4. Impact of absorptions from solvated electron and $\mathrm{Br}_{2} \mathrm{~F}^{-\bullet}$ at low $\left[\mathrm{Br}{ }_{2} \mathrm{~F}\right]$, and their mitigation by adding $0.5 \mathrm{M}$ diboromomethane.

Here we discuss the fate of electrons from ionizations in solutions with $\mathrm{Br}_{2} \mathrm{~F}$ in THF. Transient absorption data at $950 \mathrm{~nm}$ following radiolysis for low concentrations of $\mathrm{Br} 2 \mathrm{~F}$ in $\mathrm{THF}$ without $\mathrm{CH} 2 \mathrm{Br} 2$ (Ar saturated) are shown in Figure S4.1. At $950 \mathrm{~nm}$, solvated electrons absorb more strongly than at $770 \mathrm{~nm}$. At the same time, the extinction coefficient of $\mathrm{Br}_{2} \mathrm{~F}^{+\bullet}$ is only $15 \%$ of the value at $770 \mathrm{~nm}$, which coupled with the low $\mathrm{Br}_{2} \mathrm{~F}^{+} \bullet$ yield, allows solvated electron absorption to dominate the signal.

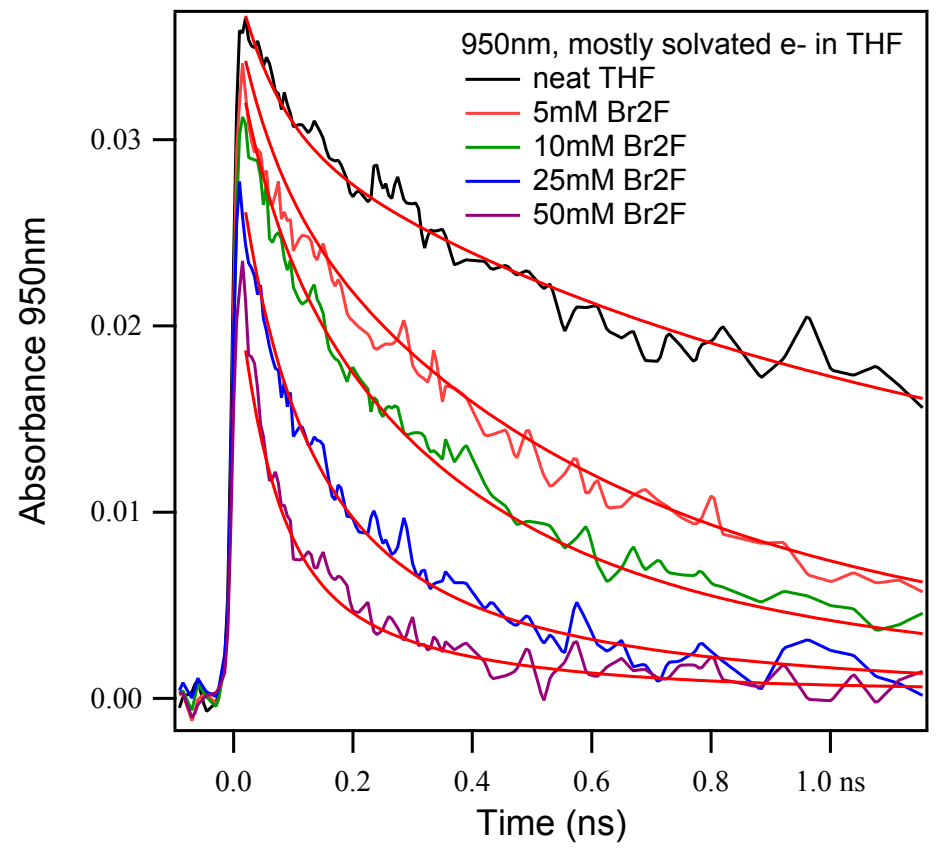

Figure S4.1: Transient absorption at $950 \mathrm{~nm}$

Initial fits were produced by fitting all of the data shown simultaneously to a model that includes a 3 exponential decay to describe the range of geminate recombination distances and rates, pre-solvated electron capture, and an electron attachment rate. These fits gave a rather large electron attachment rate of $k_{\text {att }}=1.3 \mathrm{e} 11 \mathrm{M}^{-1} \mathrm{~s}^{-1}$, with a pre-solvated electron quenching coefficient $q=14.3 \mathrm{M}^{-1}\left(\operatorname{Abs}(\mathrm{t}=0) \sim \mathrm{e}^{-q^{*} \mathrm{c}}\right.$, $\mathrm{c}=$ concentration). Fits shown in Figure S4.1 were improved slightly by including a Smoluchowski time-dependent rate term, ${ }^{6,7}$ giving a more reasonable $k_{\text {att }}=5.4 \mathrm{e} 10 \mathrm{M}^{-1} \mathrm{~s}^{-1}$, and $\mathrm{q}=11.8 \mathrm{M}^{-1}$. This rate of solvated electron attachment is well within the range of others reported in THF by Kadhum. ${ }^{8}$ We further note that the initial fit without the time-dependent term is among or greater than the very highest rates, thus likely suspect. The quenching coefficient gives a pre-solvated scavenging $\mathrm{C}_{37}$ value, at which $37 \%$ of electrons survive capture, of $\mathrm{C}_{37}=1 / q=85 \mathrm{mM}$, which is consistent with that reported by Saeki for biphenyl in THF, $87 \mathrm{mM},{ }^{9}$ with the $q$ determined with a time-dependent rate being nearly the same. 
Note that even at $50 \mathrm{mM} \mathrm{Br}_{2} \mathrm{~F}$, there are still surviving solvated electrons with a lifetime near $110 \mathrm{ps}$. At $770 \mathrm{~nm}$ the electron extinction coefficient is weak compared to $\mathrm{Br}_{2} \mathrm{~F}^{+}$, but there are many more of them than radical cations and contribute a noticeable fast decay to all of the data. These electrons are captured to make $\mathrm{Br}_{2} \mathrm{~F}^{-}$. Despite the fact that this species is short lived, it gives an addition absorption that grows on the same timescale as the electron decay followed by a complex decay. The extra absorptions and complex time-dependence due to solvated electrons and $\mathrm{Br}_{2} \mathrm{~F}^{\bullet}$ make interpreting the data at $770 \mathrm{~nm}$ much more difficult and uncertain. Figure S4.2 below gives data without dibromomethane that can be compared to Figure 2 in the main manuscript that includes it.

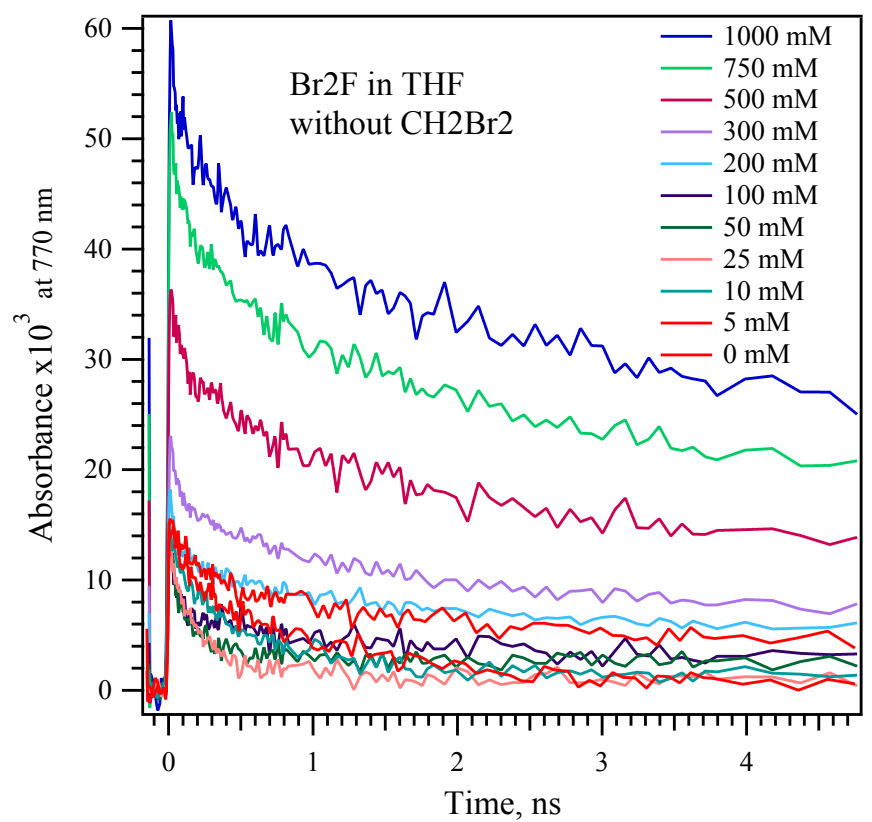

Figure S4.2: Pulse radiolysis data for $\mathrm{Br}_{2} \mathrm{~F}$ solutions that do not contain $\mathrm{CH}_{2} \mathrm{Br}_{2}$.

To remove the extra complexity in analysis, experiments described in the manuscript included $0.5 \mathrm{M}$ dibromomethane, to remove solvated electron and complex $\mathrm{Br}_{2} \mathrm{~F}^{\bullet}$ absorptions from the signals. We note that not only is $\mathrm{CH}_{2} \mathrm{Br}_{2}$ effective at removing solvated electrons and thus $\mathrm{Br}_{2} \mathrm{~F}^{-\bullet}$, we find that it may also be a very good pre-solvated electron scavenger, removing electrons on a sub- 10 ps timescale. Figure S4.3 demonstrates that $0.5 \mathrm{M}$ reduced solvated electrons by at least an order of magnitude. The lack of a decay in the remainder indicates a different species than solvated electrons - this is likely a very weak absorption of a THF radical, likely the one produced after the $0.5 \mathrm{ps}$ proton transfer from $\mathrm{THF}^{+}$to a neighboring THF molecule. Thus the data below suggests that there is essentially no solvated electrons left in the presence of $0.5 \mathrm{M} \mathrm{CH}_{2} \mathrm{Br}_{2}$, even at times as early as $10-15 \mathrm{ps}$, and there is not evidence for the predicted 25 ps decay due to e- reacting with $\mathrm{CH}_{2} \mathrm{Br}_{2}$. While it is possible this is simply due to an underestimated rate with e- or time-dependent rates of reaction, it seems plausible that scavenging of e- prior to solvation is also important. 


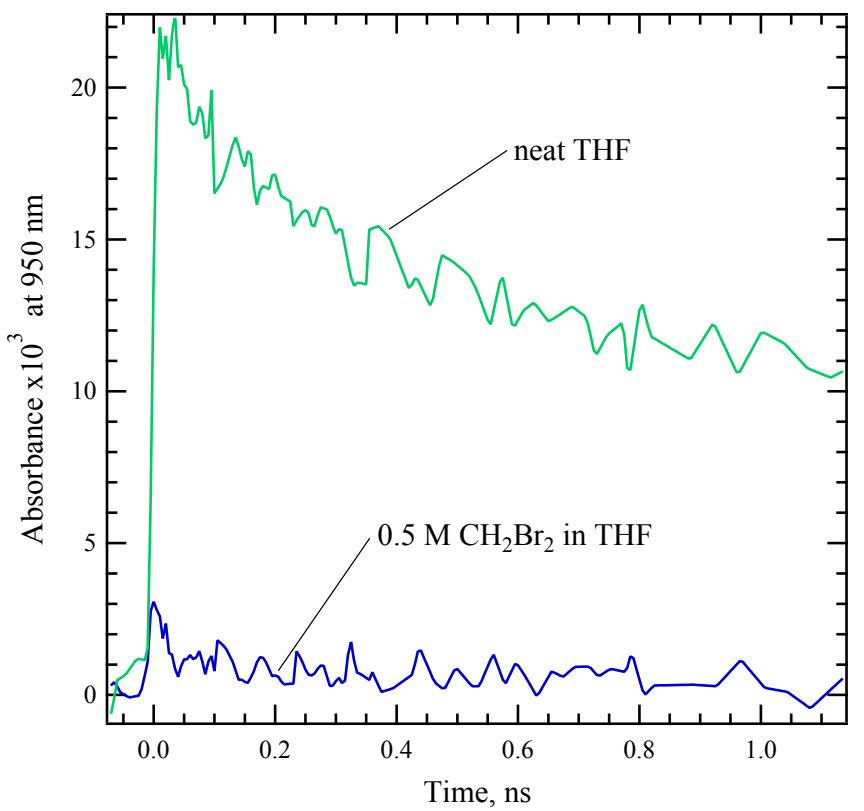

Figure S4.3: Essentially complete quenching of solvated electrons in THF by $\mathrm{CH}_{2} \mathrm{Br}_{2}$. 
Section S5. Comparison of data from different time-resolution experiments, at room temperature.

In Figure S5.1 below, we compare $\sim 1$ ns resolution photodiode/transient digitizer data and $10-15$ ps resolution OFSS data, with fits extrapolated to show the intercept at $\mathrm{t}=0$. Note that fit shown for the OFSS data has had the fast component due to $\mathrm{Br}_{2} \mathrm{~F}^{\bullet}$ subtracted out. Fits with digitizer data give a $37 \%$ smaller $\mathrm{t}=0$ value of the absorbance, due to recombination that occurs on faster timescales than the digitizer experiment is sensitive to.

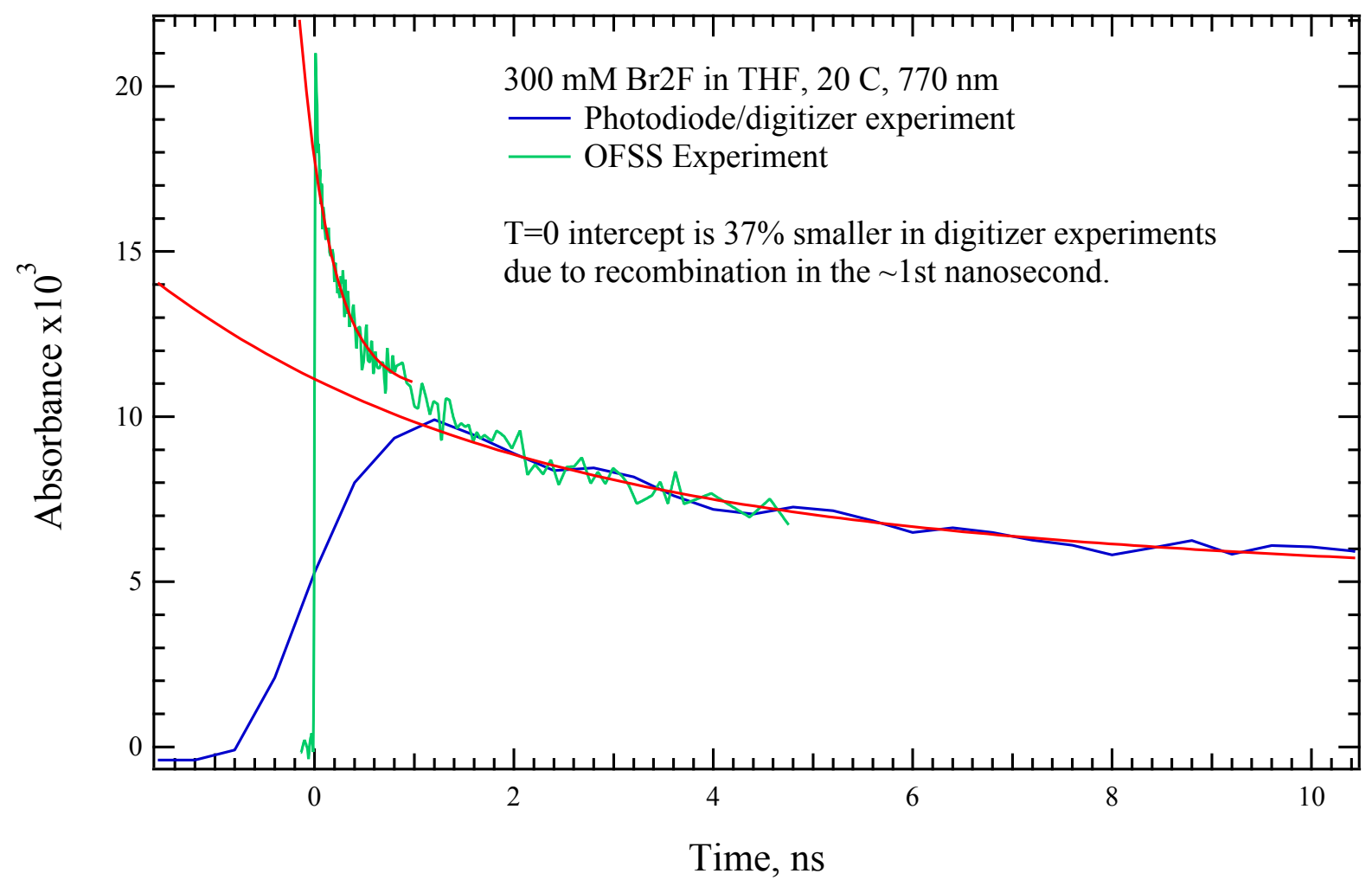

Figure S5.1: Comparison of data and fits to obtain $\mathrm{t}=0$ absorbance due to $\mathrm{Br} 2 \mathrm{~F}$ from experiments with different time resolution: OFSS (15 ps), digitizer ( $\sim \mathrm{ns})$. 
Section S6. Impact of side chains on $\mathrm{Br}_{2} \mathrm{~F}^{+} \bullet$ production.

In Figure $\mathrm{S} 6.1$ below, we show data from $500 \mathrm{mM}$ samples of $\mathrm{Br}_{2} \mathrm{~F}$ and a version missing the hexyl side chains, 2,7-dibromofluorene. $500 \mathrm{mM}$ was near the limit of solubility for dibromofluorene. This molecule has 96 fewer electrons (38\%) than $\mathrm{Br}_{2} \mathrm{~F}$ with 252 electrons/molecule, so we expect that the direct ionization yield in dibromofluorene $\left(\mathrm{G}_{\mathrm{dir}} * f_{e}^{\mathrm{Br}_{2} \mathrm{~F}}\right)$ would be $38 \%$ smaller than in $\mathrm{Br}_{2} \mathrm{~F}$ if all ionizations in the hexyl chains transfer to the $\mathrm{Br}_{2} \mathrm{~F}$ aromatic core. This gives a prediction of a $20-27 \%$ smaller observed yield for dibromofluorene, assuming $\mathrm{G}_{\mathrm{dir}}$ has a range of 3-4 / $100 \mathrm{eV}$.

Data were fit in the same way as all $\mathrm{Br}_{2} \mathrm{~F}$ samples, ignoring the fast $\sim 25$ ps component. From the fits below, the $t=0$ yield decreases by $19.2 \%$. Being slightly smaller than predicted may imply that a small number of ionizations on the hexyl chains do not make it to the core, but rather transfer to THF. Note that the alkyl chains will NOT have an antenna effect in THF, as it is uphill in energy to transfer a hole from THF to a hexyl chain by $\sim 0.7 \mathrm{eV}$ (dft, b3lyp/6-31+g*, scrf-thf).

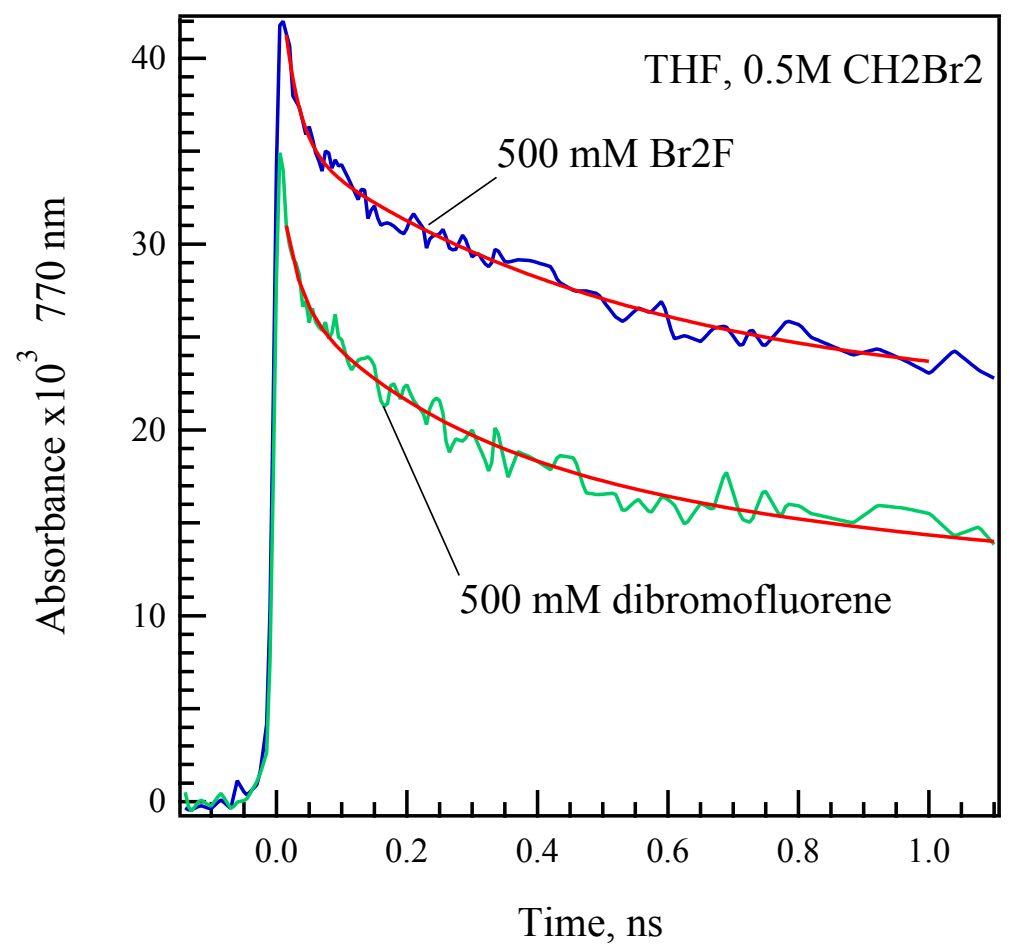

Figure S6.1: Comparison of pulse radiolysis data of samples containing hole scavengers with and without dihexyl side chains. 
Section S7: Complimentary experiments using biphenyl (BP) as a hole scavenger in place of $\mathrm{Br}_{2} \mathrm{~F}$.

The computed driving force for the hole transfer from $\mathrm{THF}^{+\bullet}$ to $\mathrm{BP}$ is $\Delta \mathrm{E}=-0.90 \mathrm{eV}$, only slightly less than for $\mathrm{Br}_{2} \mathrm{~F},-1.06 \mathrm{eV}\left(\mathrm{B} 3 \mathrm{LYP} / 6-31+\mathrm{G}^{*} / \mathrm{SCRF}=\mathrm{THF}\right)$. BP is a good comparison because it lacks the $\mathrm{Br}$ atoms and hexyl side chains that $\mathrm{Br}_{2} \mathrm{~F}$ has. It thus produced a much lower direct ionization yield, about $1 / 3$ of that of $\mathrm{Br}_{2} \mathrm{~F}$. On the other hand, these experiments are more complex to interpret as both radical cations and anions are formed and are long lived and absorb at $700 \mathrm{~nm}$. We note that radical cations prepared in low temperature glasses appear to have a stronger absorbance at $700 \mathrm{~nm}$, with radical anions shifted to the blue by $50 \mathrm{~nm} .{ }^{2}$ At room temperature these spectra broaden and may make both species with more similar

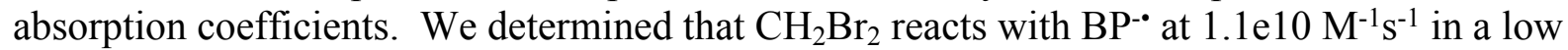
concentration BP solution. This is responsible for the $\sim 125$ ps decay in the data in the traces in Figure S7.1 below.

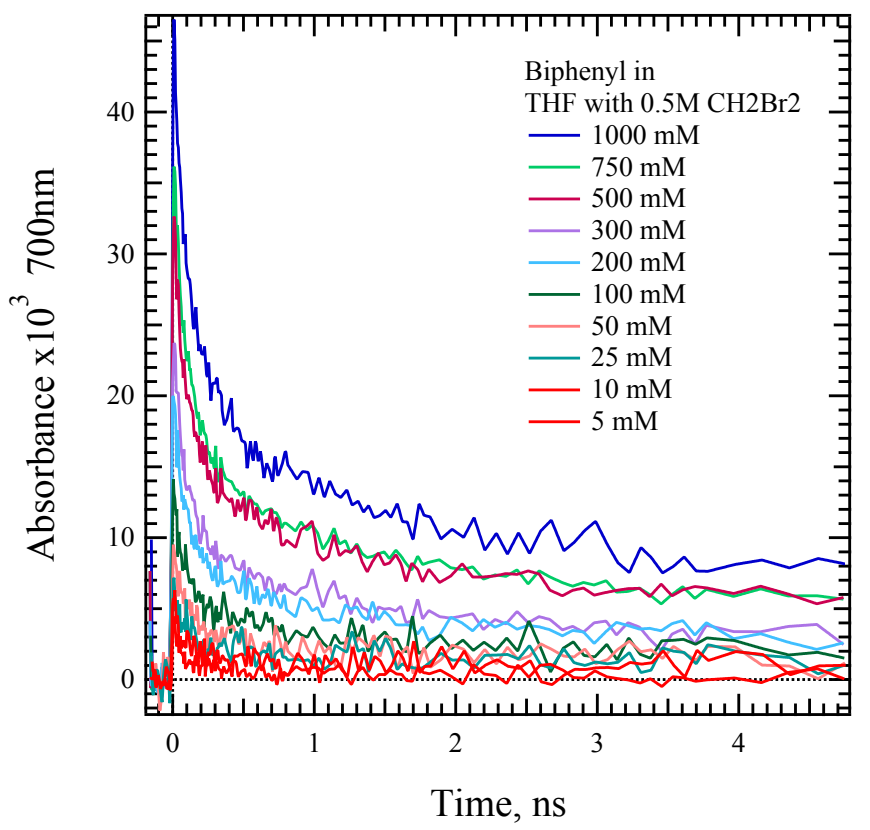

Figure S7.1: $0.5 \mathrm{M} \mathrm{CH}_{2} \mathrm{Br}_{2}$ removes the excess electron from $\mathrm{BP}^{-\bullet}$ on a $\sim 125$ ps timescale, exposing absorptions due to $\mathrm{BP}^{+\cdot}$.

This data was fit in the same manner as $\mathrm{Br}_{2} \mathrm{~F}$ data in the manuscript, holding the decay rate due to the reaction of $\mathrm{CH}_{2} \mathrm{Br}_{2}$ with $\mathrm{BP} \cdot \bullet$ constant. The remainder of the signal is due to $\mathrm{BP}^{+\bullet}$. Given that anions obscure the signal at short times, the extrapolation of the $\mathrm{BP}^{+\bullet}$ signal to $\mathrm{t}=0$ is less sure than with $\mathrm{Br}_{2} \mathrm{~F}$, and may miss faster transients.

If we compare the difference of the observed yield and direct yield $\left(\mathrm{G}_{\mathrm{obs}}-\mathrm{G}_{\mathrm{dir}}\right)$ with both $\mathrm{BP}$ and $\mathrm{Br}_{2} \mathrm{~F}$ scavengers (with and without side-chains included in the direct yield), we obtain the results in Figure S7.2 below. These graphs show that the scavenger radical cation yield produced by transfer from $\mathrm{THF}^{+}$is remarkably similar in $\mathrm{Br}_{2} \mathrm{~F}$ and $\mathrm{BP}$, as one might expect for these similar molecules. Note that if side chains are not included in the direct ionization yield of $\mathrm{Br}_{2} \mathrm{~F}$, the comparison is poor, supporting including them in them analysis for $\mathrm{Br}_{2} \mathrm{~F}$. The graphs also suggest that the direct ionization yield of the 2 solutes is between 3 and $4 / 100 \mathrm{eV}$, as $\mathrm{BP}$ with $\mathrm{G}_{\mathrm{dir}}=3$ lies a bit below $\mathrm{Br}_{2} \mathrm{~F}$, while with $\mathrm{G}_{\mathrm{dir}}=4$ lies a bit above. 

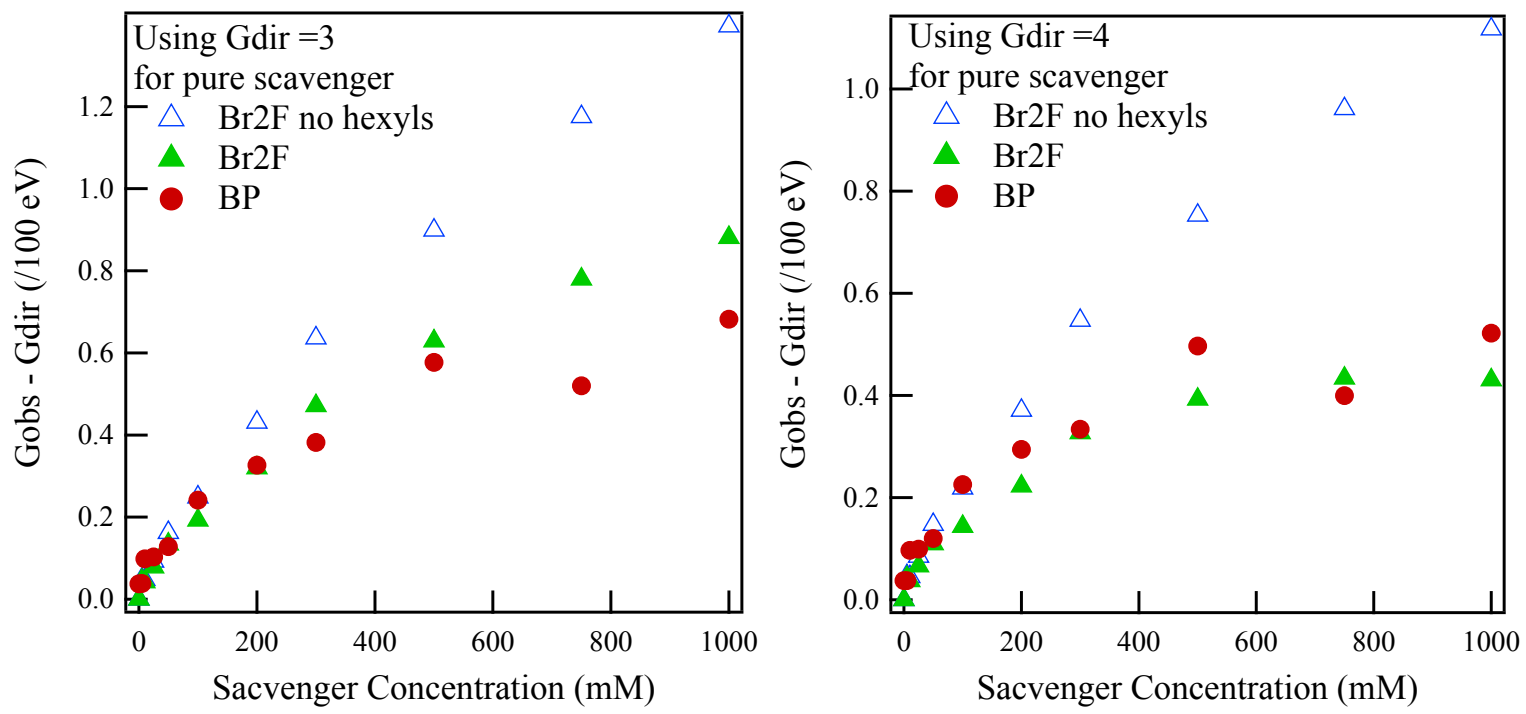

Figure S7.2: Comparison of the difference in the observed radical cation yield and direct solute ionization yield $\left(\mathrm{G}_{\mathrm{obs}}-\mathrm{G}_{\mathrm{dir}}\right)$ for $\mathrm{Br}_{2} \mathrm{~F}$ and $\mathrm{BP}$ solutes in THF with $0.5 \mathrm{M} \mathrm{CH}_{2} \mathrm{Br}_{2}$. 
Section S8. Table of Electron densities of each component in samples.

* All samples contain $0.5 \mathrm{M} \mathrm{CH}_{2} \mathrm{Br}_{2}: 78 \mathrm{e}-/ \mathrm{molecule},=0.039 \mathrm{~mol} \mathrm{e}-/ \mathrm{cm}^{3}$ in samples THF: 40 e-/molecule

$\mathrm{Br}_{2} \mathrm{~F}$ (including side-chains): 252 e-/molecule

$f_{\mathrm{e}}=$ fraction of total electron density

\begin{tabular}{llllllll}
$\begin{array}{l}{[\mathrm{Br}} \\
2 \mathrm{~F}] \\
\left(\mathrm{mol} / \mathrm{dm}^{3}\right)\end{array}$ & $\begin{array}{l}\text { Density } \\
\left(\mathrm{g} / \mathrm{cm}^{3}\right)\end{array}$ & $\begin{array}{l}{[\mathrm{THF}]} \\
\left(\mathrm{mol} / \mathrm{dm}^{3}\right)\end{array}$ & $\begin{array}{l}\mathrm{Br} \mathrm{F}_{2} \mathrm{~mol} \\
\mathrm{e}-/ \mathrm{cm}^{3}\end{array}$ & $\begin{array}{l}\mathrm{THF} \mathrm{mol} \\
\mathrm{e}-/ \mathrm{cm}^{3}\end{array}$ & $\begin{array}{l}\mathrm{Br}_{2} \mathrm{~F} \\
f_{\mathrm{e}}\end{array}$ & $\begin{array}{l}\mathrm{THF} \\
f_{\mathrm{e}}\end{array}$ & $\begin{array}{l}\mathrm{CH}_{2} \mathrm{Br}_{2} \\
f_{\mathrm{e}}\end{array}$ \\
\hline 0 & 0.933 & 11.727 & 0.000 & 0.469 & 0.000 & 0.923 & 0.077 \\
5 & 0.933 & 11.701 & 0.001 & 0.468 & 0.002 & 0.921 & 0.077 \\
10 & 0.934 & 11.676 & 0.003 & 0.467 & 0.005 & 0.918 & 0.077 \\
25 & 0.936 & 11.601 & 0.006 & 0.464 & 0.012 & 0.911 & 0.077 \\
50 & 0.939 & 11.475 & 0.013 & 0.459 & 0.025 & 0.899 & 0.076 \\
100 & 0.946 & 11.224 & 0.025 & 0.449 & 0.049 & 0.875 & 0.076 \\
200 & 0.959 & 10.722 & 0.050 & 0.429 & 0.097 & 0.827 & 0.075 \\
300 & 0.972 & 10.219 & 0.076 & 0.409 & 0.144 & 0.781 & 0.075 \\
500 & 0.998 & 9.214 & 0.126 & 0.369 & 0.236 & 0.691 & 0.073 \\
750 & 1.030 & 7.958 & 0.189 & 0.318 & 0.346 & 0.583 & 0.071 \\
1000 & 1.063 & 6.701 & 0.252 & 0.268 & 0.451 & 0.479 & 0.070
\end{tabular}

In the manuscript we treat the THF and $\mathrm{CH}_{2} \mathrm{Br}_{2}$ together as the solvent, summing their fractions of the electron density. We note that holes from $\mathrm{CH}_{2} \mathrm{Br}_{2}$ have a chance to be captured by $\mathrm{Br}_{2} \mathrm{~F}$, but because $\left[\mathrm{Br}_{2} \mathrm{~F}\right]<<[\mathrm{THF}]$ most holes likely transfer to THF first, then are possible to be captured by $\mathrm{Br}_{2} \mathrm{~F}$ as described in the paper. The fraction of the sample electron density due $\mathrm{CH}_{2} \mathrm{Br}_{2}$ is less than $8 \%$ for all samples, so any errors from the approach are likely small. 


\section{References:}

1. Takeda, N.; Poliakov, P. V.; Cook, A. R.; Miller, J. R. "Faster Dissociation: Measured Rates and Computed Effects on Barriers in Aryl Halide Radical Anions" J. Am. Chem. Soc. 2004, 126, 4301-4309. doi:10.1021/ja0389671

2. Shida, T. Electronic Absorption Spectra of Radical Ions; Elsevier Science Publishers B.V.: Amsterdam, The Netherlands, 1988.

3. Bird, M. J.; Cook, A. R.; Zamadar, M.; Asaoka, S.; Miller, J. R. "Pushing the Limits of the Electrochemical Window with Pulse Radiolysis in Chloroform" Phys. Chem. Chem. Phys. 2020, 22, 14660-14670. doi:10.1039/D0CP01948H

4. Gould, I. R.; Ege, D.; Moser, J. E.; Farid, S. "Efficiencies of Photoinduced ElectronTransfer Reactions: Role of the Marcus Inverted Region in Return Electron Transfer within Geminate Radical-Ion Pairs" J. Am. Chem. Soc. 1990, 112, 4290-4301. doi:10.1021/ja00167a027

5. Merkel, P. B.; Luo, P.; Dinnocenzo, J. P.; Farid, S. "Accurate Oxidation Potentials of Benzene and Biphenyl Derivatives Via Electron-Transfer Equilibria and Transient Kinetics" $J$. Org. Chem. 2009, 74, 5163-5173. doi:10.1021/jo9011267

6. Noyes, R. M. "Effects of Diffusion Rates on Chemical Kinetics" Prog. React. Kinet. Mech. 1961, 1, 129-160.

7. Andre, J. C.; Niclause, M.; Ware, W. R. "Kinetics of Partly Diffusion Controlled Reactions. I. Transient and Apparent Transient Effect in Fluorescence Quenching" Chem. Phys. 1978, 28, 371-377. doi:10.1016/0301-0104(78)80014-7

8. Kadhum, A. A. H.; Salmon, G. A. "Reactivity of Solvated Electrons in Tetrahydrofuran" J. Chem. Soc., Faraday Trans. 1 1986, 82, 2521-2530. doi:10.1039/F19868202521

9. $\quad$ Saeki, A.; Kozawa, T.; Ohnishi, Y.; Tagawa, S. "Reactivity between Biphenyl and Precursor of Solvated Electrons in Tetrahydrofuran Measured by Picosecond Pulse Radiolysis in near-Ultraviolet, Visible, and Infrared" J. Phys. Chem. A 2007, 111, 1229-1235. doi:10.1021/jp067520m 